Anuario de Estudios Medievales

43/2, julio-diciembre de 2013, pp. 777-798

ISSN 0066-5061

doi:10.3989/aem.2013.43.2.10

\title{
RATIO SUPERIOR, RATIO INFERIOR Y EL AGUSTINISMO DE TOMÁS DE AQUINO
}

\author{
RATIO SUPERIOR, RATIO INFERIOR \\ AND THE AUGUSTINIANISM OF THOMAS AQUINAS
}

PATRICIA MOYA CAÑAS
MANFRED SVENSSON

Universidad de los Andes, Santiago de Chile

Resumen: El artículo discute la recepción que hace Tomás de Aquino de la distinción agustiniana entre razón superior e inferior. Si bien no se trata de uno de los tópicos centrales de la doctrina tomasiana, es un elemento significativo a la hora de considerar dentro de la obra de Tomás la presencia de patrones agustinianos de pensamiento que no sean primordialmente teológicos. Tras discutir de modo general la presencia de esta distinción en la obra del aquinate, y los estudios previos sobre este binomio, se procede a discutir su uso por parte de Tomás de Aquino ante tres problemas específicos: la distinción entre géneros de vida, la división de las facultades humanas, y el problema moral de la delectación morosa.

Palabras claves: razón superior e inferior; Agustín; Tomás de Aquino; agustinismo.

\begin{abstract}
This article discusses Aquinas' reception of the Augustinian distinction between ratio inferior and superior. Though not a central aspect of Aquinas' thought, it is a significant pointer to the presence of Augustinian patterns of thought in a non-theological part of his work. After a general survey of the presence of this distinction in the opera omnia of Aquinas, his use of this topic in some specific instances is discussed: the distinction between contemplative and active life, the division of human faculties, and the moral problem of peevish delight.
\end{abstract}

Keywords: superior and inferior reason; Augustine; Aquinas; agustinianism.

\section{SUMARIO}

1. Introducción.- 2. Precisiones sobre la naturaleza del binomio en Agustín.- 3. La recepción tomasiana del binomio.- 4. La comprensión tomasiana del binomio.- 4.1. Los géneros de vida.- 4.2. Las diversas facultades de la persona humana.- 4.3. El uso de la razón superior e inferior en el plano moral: la delectación morosa.- 5. Conclusiones.- 6. Bibliografía citada. 


\section{INTRODUCCIÓN}

El presente artículo se enmarca en el contexto del creciente reconocimiento del agustinismo de Tomás de Aquino. En contraste con una época en la que la filosofía de la Edad Media tardía era dividida en corrientes agustinianas y corrientes aristotélicas, hoy estamos ante una mayor valoración del papel primordial que tiene para el tardío siglo XIII más bien el conflicto entre diversos aristotelismos -como atestigua el creciente estudio de la condena de 1277-, y con ello también ha habido una mayor conciencia del extendido agustinismo del periodo. El genio de alguien como Tomás de Aquino resalta así precisamente como genio unificador, que logra una síntesis entre posiciones aparentemente inconmensurables, no como el representante de uno de los partidos en pugna. Tal impresión parece irse consolidando no sólo entre los estudiosos de la filosofía medieval, sino también entre analistas más generales de la cultura ${ }^{1}$. Pero esto obliga, por supuesto, a una mayor precisión respecto del sentido en que cada autor es aristotélico o agustiniano. En el caso de Tomás de Aquino, el camino por el que acostumbra resolverse tal cuestión, es el de grosso modo reconocer la impronta de Agustín sobre su pensamiento, pero en gran medida relegándola a la teología. Así ocurre todavía en la última obra colectiva sobre el agustinismo de Tomás, con contribuciones casi exclusivamente centradas en la teología del aquinate. El resultado es que el creciente reconocimiento de su agustinismo apenas ofrece una concepción más enriquecida de su filosofía² .

El tópico que aquí abordamos es el uso tomasiano del binomio ratio superior y ratio inferior que en Agustín se encuentra vinculado a la distinción entre scientia y sapientia. La distinción entre dos usos de la razón constituye un significativo elemento agustiniano en la filosofía de Tomás de Aquino. Así, por lo demás, ha sido reconocido por mucho tiempo. Ya en 1940 Marie-Dominique Chenu escribió un breve artículo presentando el tema como un descuidado capítulo de philosophie chrétienne $e^{3}$. Sería un típico elemento cristiano de la filosofía medieval que habría sido oscurecido por la posterior fijación de la neoescolástica en los elementos puramente aristotélicos de la escolástica medieval. Chenu lleva en cierto sentido la razón respecto de la originalidad de esta distinción entre formas de conocimiento, como algo que hizo su aparición tras la llegada del cristianismo. Pero en cuanto a la centralidad del tópico para

\footnotetext{
${ }^{1}$ Así, por ejemplo, en A. MacIntyre, Tres versiones rivales de la ética.

${ }^{2}$ M. Dauphinais, B. David, M. Levering (eds.) Aquinas the Augustinian. Excepciones a esto pueden ser encontradas en Th. Osborne, The Augustinianism y P. Weithman, Augustine and Aquinas.

${ }^{3}$ M-D. Chenu, Ratio superior et inferior.
} 
la filosofía medieval, cabe cierto escepticismo. Quien más ha hecho por poner este problema en su justa dimensión es Robert Mulligan, con dos artículos sobre los antecedentes históricos de la distinción entre razón superior e inferior, y sobre la misma distinción en Alberto Magno y Tomás de Aquino ${ }^{4}$. Sus tesis parecen ser hasta tal punto conclusivas, que se podría pensar que la discusión está cerrada. En efecto, no hay contribuciones científicas sobre este problema desde los artículos de Mulligan en 1955 y 1956. El balance de los mismos puede ser resumido en los siguientes términos: Tomás de Aquino habría usado esta distinción en una variedad de lugares, pero siguiendo en ello usos tradicionales; habría librado a la distinción de sus restos neoplatónicos, pero no habría explotado toda la riqueza de la misma, lo cual daría testimonio suficiente de que no se trata de una distinción capital para el pensamiento tomista.

En líneas generales, como descripción del lugar que estas nociones tienen en la obra de Tomás de Aquino, creemos que se puede asentir a las conclusiones de Mulligan. Con todo, es posible hacer algunas aclaraciones ulteriores sobre el origen agustiniano de la pareja conceptual, su posterior transmisión, y la comprensión que tiene Tomás de Aquino del carácter específicamente agustiniano de la misma. Eso es lo que busca el presente artículo.

\section{PRECISIONES SOBRE LA NATURALEZA DEL BINOMIO EN AGUSTÍN}

Para comenzar conviene hacer varias aclaraciones sobre la naturaleza de esta distinción en Agustín, y en particular sobre su origen específicamente agustiniano. La literatura contemporánea sobre Agustín ha recorrido en este punto algunos caminos equivocados. Éstos son en parte comprensibles por las dificultades de traducción que naturalmente causa un término como scientia. Traducido en ediciones modernas del De Trinitate como Wissenschaft, science o ciencia, se ha tendido con frecuencia a ver aquí un reconocimiento por parte de Agustín de la importancia de las ciencias naturales. Hay de esta interpretación ejemplos elocuentes y de la pluma de significativos estudiosos de Agustín. Así, Johannes Hessen ha entendido esta distinción de modo tal que la scientia sea un conocimiento empírico que opera por abstracción ${ }^{5}$. La presencia de la distinción sería así un indicio de que, contra una muy difundida impresión, en Agustín sî habría preocupación por el conocimiento del mundo natural. De modo análogo, Ronald Nash ha entendido la scientia como el conocimiento técnico o productivo, de modo que la scientia permite al hombre ocuparse de los cultivos, de la

${ }^{4}$ R. Mulligan, Ratio superior and ratio inferior: The Historical Background y Ratio inferior and ratio superior in St. Albert and St. Thomas.

${ }^{5}$ J. Hessen, Die Begründung der Erkenntnis nach dem heiligen Augustinus, pp. 38-47. 
construcción y de la guerra ${ }^{6}$. Sin embargo, una mirada a ulteriores alternativas de traducción abre otras posibilidades de interpretación. Scientia, en efecto, no es más que el sustantivo de scire. No es "ciencia", sino "conocimiento", y si dirigimos la mirada al libro XII del De Trinitate de Agustín podremos averiguar de qué tipo de conocimiento se trata. En efecto, si bien Agustín no ofrece definiciones precisas de lo que entiende bajo razón superior e inferior, ni sus respectivas excelencias, scientia y sapientia, sí ilumina estas formas de conocimiento a partir de distintos textos bíblicos. De hecho, la distinción misma viene de un texto paulino (I Corintios 12,8). Pero es en Job que Agustín cree encontrar la explicación de los contenidos de la distinción, pues ahí -en el texto latino recibido por Agustín- se nos dice que la piedad, es sabiduría, y evitar el mal, conocimiento (scientia) (Job 28, 28) ${ }^{7}$. A la luz de este texto, y del modo en que el tema es expuesto en lo que resta del De Trinitate, se trata de una distinción no entre dos formas del saber teórico -sophia y episteme aristotélicos-, sino entre un saber contemplativo y un saber práctico.

Pero una distinción semejante es algo llamativo en un pensador platónico. Se trata, en efecto, de una distinción que el mismo Agustín no realiza en su obra temprana, en la que claramente predomina una concepción unitaria de la sabiduría ${ }^{8}$. Contrariamente a lo que podrían hacer pensar textos a los que refiere Mulligan ${ }^{9}$, cuando Agustín, en su obra temprana, usa los términos scientia y sapientia se trata invariablemente de un uso sinónimo, no de una distinción ${ }^{10}$. Por lo demás, tal variedad de hábitos intelectuales descansa sobre un tipo de partición del alma que tampoco se encuentra en sus escritos de dicho período ${ }^{11}$. Se trata pues de una posición a la que Agustín llega como parte de su lento pero consistente desarrollo intelectual. Ahora bien, aquello a lo que llega tampoco debe ser identificado con la separación aristotélica entre saber práctico y saber teórico. Si la distinción entre el saber práctico y el contemplativo lo convierte en un caso singular en la tradición platónica, el modo en que vincula ambos saberes lo separa del aristotelismo. En efecto, si bien a la sapientia es asignada una función primordialmente contemplativa, y a la scientia una primordialmente práctica, ambas pueden ser aptamente caracterizadas como bidireccionales. En efecto, según explica Agustín en De Trinitate

\footnotetext{
${ }^{6}$ R. Nash, The Light of the Mind, p. 8.

${ }^{7}$ De Trinitate, XII, 14, 22. "Ecce pietas est sapientia; abstinere autem a malis scientia est".

${ }^{8}$ Para su evolución en esta materia véase M. Svensson, Theorie und Praxis bei Augustin. pp. 82-120.

${ }^{9}$ En Ratio inferior and ratio superior in St. Albert and St. Thomas p. 340 refiere por ejemplo a De diversis quaestionibus LXXIII, 46, texto que comentamos más abajo.

${ }^{10}$ Véase, por ejemplo, De Academicis, I, 6, 16.

${ }^{11}$ La unidad de la parte racional del alma en los escritos tempranos de Agustín es particularmente evidente en De Genesi contra Manichaeos, II, 11, 15-16.
} 
XII, 22, 24, aunque la scientia es primordialmente práctica, opera en parte como sistematización de lo contemplado en la sapientia. En esos términos se expresa no sólo en el De Trinitate, donde la scientia se constituye precisamente por un "rumiar" respecto de los momentos de contemplación ${ }^{12}$. Algo similar se encuentra ya prefigurado en los ascensos de las Confessiones: en tres ocasiones Agustín tiene experiencias contemplativas cuyo patrón común es que a pesar de la fugacidad de la experiencia, ésta produce cierto cambio en la visión de mundo, al menos en términos de captación de (y creciente conformidad con) la propia finitud ${ }^{13}$. La scientia tiene una mirada hacia arriba, no sólo hacia abajo. Pero también hay un actuar de la sapientia sobre la scientia. Pues aunque ésta es descrita como conocimiento práctico, la concreción en una obra externa requiere según Agustín del consentimiento de la sapientia ${ }^{14}$, consentimiento que bien podemos interpretar como acto de la conciencia, aunque aquí no aparezca el término.

Esta caracterización nos permite hacer algunas precisiones ulteriores respecto del modo en que Mulligan ha tratado el trasfondo preagustiniano y la posterior transmisión medieval de esta idea. En efecto, si bien Mulligan reconoce a Agustín como la principal fuente de los escolásticos para esta distinción, afirma que la misma tendría una prehistoria mucho más extensa y compleja. Agustín habría tomado la distinción de las Enéadas de Plotino, y de dicha obra saldría no sólo una tradición que pasa por Agustín, sino también otra que pasa por el mundo árabe para llegar luego a la obra del Dominico Gundisalvo. Es una tradición que, con Mulligan, podemos caracterizar como la de los "dos rostros" del alma. Pero es nuestro parecer que dichas dos tradiciones deben ser separadas de un modo mucho más radical, poniendo en duda su origen en común. El punto de contacto ofrecido por Mulligan es, en efecto, la descripción de los dos "rostros del alma", que en apariencia se encuentra presente en cada eslabón de esta tradición. Al respecto cabe plantear preguntas críticas en dos direcciones: en primer lugar, respecto del sentido que tiene tal tópico en Plotino, y en segundo lugar respecto del eventual vínculo que la idea de "rostros del alma" tenga en Agustín con su distinción entre razón superior e inferior.

La segunda de estas preguntas puede ser abordada de un modo muy sencillo, pues como prueba textual a favor de su posición Mulligan ofrece

12 De Trinitate, XII, 14, 23.

${ }_{13}$ Véase Confessiones, VII, 10, 16; VII, 17, 23 y IX, 10, 24-25. En esto estamos adhiriendo a aquellas interpretaciones de estos tres ascensos que los ven como igualmente logrados (o igualmente fracasados), acentuando no la diferencia entre los dos primeros ascensos hechos como pagano y el tercer ascenso hecho como cristiano, sino la diferencia en la interpretación que Agustín hace de una misma experiencia.

${ }^{14}$ De Trinitate, XII, 8, 13. 
un solo texto, del breve pero importante tratado "De Ideis" contenido en el De diversis quaestionibus LXXXIII. Ahí Agustín habla sobre el conocimiento de las ideas como algo que el alma sólo puede alcanzar mediante su parte superior, aquélla por la cual sobresale, por la mente y razón, que es como su ojo o rostro interior e inteligible ${ }^{15}$. Ahora bien, tales palabras de Agustín sólo acreditan la existencia de la imagen de una facies animae en su obra, y el hecho de que es con este rostro -la razón- que es posible conocer las ideas. Pero lo que no acredita es conexión alguna entre la idea plotiniana de dos rostros del alma y la distinción que Agustín -años más tarde- desarrollaría entre dos formas de la racionalidad. En efecto, lo que el texto muestra es más bien la independencia de ambas cuestiones, llevándonos de regreso a la primera pregunta. Mulligan parece ser aquí presa de un error muy sencillo: ha identificado una distinción (no sólo plotiniana, sino muy común) entre partes del alma, con una distinción entre partes de la razón. Esto puede verse con claridad en el paralelismo que intenta trazar entre textos de Agustín y Plotino, una comparación que en realidad saca a la luz más diferencias que semejanzas ${ }^{16}$. Plotino afirma, en efecto, que toda alma tiene dos partes, una inferior por el lado corporal y otra superior por el lado del principio intelectual ${ }^{17}$, pero eso no puede en modo alguno considerarse equivalente a una distinción entre dos partes de la razón. Por decirlo de otro modo: la interpretación de Mulligan implicaría que en Plotino las "partes inferiores" pudiesen ser racionales, pero eso es algo que sólo encontraremos más tarde, en Agustín. Esto mismo vale, por cierto, para eventuales intermediarios entre Plotino y Agustín. Mulligan cree encontrar un caso de tal transmisión en Mario Victorino, pero el texto al que somos referidos es, una vez más, uno que presenta una división del alma, no una división de la razón ${ }^{18}$. En suma, ciertamente son variadas las corrientes que presentan divisiones del alma y funciones distintas de la razón, pero precisamente esa variedad es la que nos obliga a una pesquisa más específica cuando se trata de influencias. Y al realizar tal pesquisa, puede afirmarse que Agustín, más que beber de una tradición plotiniana en esta materia, desarrolló en su obra tardía una posición considerablemente original, consistente no en una general división del alma, sino en una división de la razón que por sus relaciones recíprocas sigue sin embargo enmarcada en la tradición platónica.

15 De diversis quaestionibus LXXIII, 46, 2. "Anima vero negatur eas intueri posse nisi rationalis, ea sui parte qua excellit, id est, ipsa mente atque ratione, quasi quadam facie vel oculo suo interiore atque intellegibili"'.

${ }^{16}$ La tabla contenida en R. Mulligan, Ratio superior and ratio inferior, pp. 12-13 debe ser leída con precaución, pues mezcla cita literal de ambos autores con interpretación de Mulligan.

${ }^{17}$ Enéadas, IV, 8, 8.

18 R. Mulligan, Ratio superior and ratio inferior, p.10. Cf. el texto de Mario Victorino en Adversus Arium PL 8 1086-87. 


\section{LA RECEPCIÓN TOMASIANA DEL BINOMIO}

Antes de abordar la pregunta por el grado en que Tomás de Aquino ha comprendido la naturaleza específicamente agustiniana que hasta aquí hemos buscado destacar en esta distinción, conviene tener una impresión general de los lugares y el tipo de materias que lo llevan a usarla. Hay un pequeño conjunto de textos que hemos dejado fuera de la discusión, por tratarse de textos en que Tomás usa la distinción, pero sólo en objeciones o en respuestas a las mismas, de un modo que bien puede ser descartado como algo que no desempeña papel alguno en su pensamiento. Dejando de lado esos casos, el primer lugar natural para la discusión sobre la razón superior e inferior es la sección de las Sententiae en que Pedro Lombardo inserta los textos correspondientes de Agustín: II Sent., d. 24, 9-12. Sólo al final, en d. 24, 12, 6, Pedro Lombardo inserta una observación propia, para aclarar por qué incluyó esta sección. Ahí afirma que hizo esto:

para que sea conocida de modo más pleno la naturaleza del alma, y para que se comprenda conforme a cuál de sus partes hay en ella libre albedrío, esto es, según la razón. De ahí nace todo pecado mortal, pero no todo venial, pues hay uno que se da en el solo movimiento de la sensualidad ${ }^{19}$.

Se trata pues para Pedro Lombardo de un capítulo de antropología cuya inserción tiene un claro propósito moral. Tal contexto da lugar a dos discusiones estrechamente vinculadas, pero que en el desarrollo subsiguiente presentaremos de modo separado: por una parte, la pregunta más puramente antropológica respecto de la medida en que aquí se esté o no distinguiendo facultades; por otra parte, la pregunta por la delectación morosa. La primera de estas preguntas es abordada por Tomás de Aquino no sólo en el comentario al lugar respectivo de las Sententiae, sino de modo más detenido en De Veritate q. 15, a. 2 y Summa Theologiae, I, 79, 9. En cuanto a la delectación morosa, ésta es tratada en In IV libros Sententiarum, en De Veritate q. 15, a. 4, y en el contexto moral de la Secunda Secundae, en concreto en la q. 74, a. 6 y 7.

Pero si se dirige la mirada a In IV libros Sententiarum, lo más llamativo no son estos tópicos, en que es natural que Tomás de Aquino recogiera los problemas planteados por Pedro Lombardo, sino el hecho de que este

19 P. Lombardo, Sententiae in quattuor libros distinctae, II Sent. d. 24, 12, 6. "Haec de animae partibus interseruimus, ut ipsius animae natura plenius cognosceretur, et secundum quam sui portionem in ea sit liberum arbitrium intelligatur, scilicet secundum rationem; quo omne mortale peccatum geritur, sed non omne veniale, illud scilicet quod in solo motu sensualitatis exsistit". 
binomio se introduzca también en el comentario a un lugar en que el texto de Pedro Lombardo no contiene nada semejante. Esto ocurre en III Sent., d. 15 , q. 2, a. 3 , y el texto es significativo puesto que nos muestra a Tomás de Aquino usando esta noción sin verse forzado a ello por sus puntos de partida. El tópico que ahí aborda es, en efecto, el de la pasibilidad del alma de Cristo, cuestión para cuyo tratamiento vuelve a recurrir a esta distinción en Summa Theologiae III, 46, 7 y 8 y en el Compendium Theologiae. Finalmente, cabe mencionar que la pareja conceptual es incorporada por Tomás en varias ocasiones a lo largo de sus comentarios bíblicos, donde, una vez más, nada lo obligaba a esta discusión. El resultado de una revisión como ésta es pues indicador de que, si bien se puede coincidir con Mulligan en que no estamos ante uno de los conceptos fundamentales del pensamiento tomista, parece difícil descartarlo simplemente como algo incorporado por Tomás de Aquino de modo forzado, como un corpúsculo de agustinismo apenas integrado con el resto de su pensamiento.

Ahora bien, cabe notar una importante diferencia respecto de Agustín, una que no ha sido notada por los estudiosos. Ésta es que, si bien en muchos sentidos se puede decir que Tomás está usando esta herramienta de origen agustiniano en un espíritu todavía agustiniano, no obstante la ha desvinculado de su doble contexto en la obra de Agustín. Tal doble contexto consiste, en primer lugar, en que la distinción entre razón superior e inferior está al servicio (inmediato) de la distinción entre sus respectivas excelencias, $s a$ pientia y scientia, términos que en los libros XII-XIV del De Trinitate acaban siendo muchísimo más frecuentes que los relativos a la distinción entre partes de la razón. En segundo lugar, eso se encuentra a su vez al servicio de un proyecto mayor aún, el de un ascenso a través del hombre interior en búsqueda de más adecuadas imágenes de la Trinidad. Como salta a la vista, ninguno de estos dos pasos se encuentra en Tomás. Hay en su obra un uso de la distinción entre razón superior e inferior en un contexto teológico, pero no en un contexto trinitario, sino, como hemos señalado, para explicar la pasibilidad del alma de Cristo.

Pero además cabe notar que, en contraste con la mayor parte de los estudiosos contemporáneos de Agustín, Tomás de Aquino tiene una clara comprensión de la evolución intelectual del hiponense en esta materia. La consideración de dos textos nos permitirá constatar esto con claridad. El primero se encuentra en la q. 15 del De Veritate. En la respuesta a una de las objeciones, Tomás de Aquino hace notar que las tres etapas de la tentación -tentación, deleite y consentimiento, con sus paralelos en la serpiente, la mujer y el hombre- son descritas de modo diverso en el temprano comentario de Agustín De Genesi contra Manichaeos y en el posterior De Trinitate: En De Trinitate XII atribuye, en efecto, la serpiente a la sensualidad y la 
mujer a una razón inferior, mientras que en el libro contra los maniqueos había atribuido la serpiente al sentido y la mujer a la concupiscencia o sensualidad, y al hombre la razón ${ }^{20}$. Lo que Tomás de Aquino demuestra captar en tal afirmación es precisamente una evolución en dirección a la bipartición no del alma, sino de la racionalidad. Algo similar encontramos en su comentario a I de Corintios 11, el pasaje en que san Pablo llama a la mujer a cubrir su cabeza, que es uno de los textos que usa Agustín en el De Trinitate para establecer que la razón inferior debe estar bajo cierta tutela de la superior. Del comentario de Tomás al pasaje poseemos dos versiones distintas, la reportatio vulgata y la reportatio de Reginaldo de Piperno, la cual en este punto parece reflejar mejor la mente de Tomás de Aquino. Pues en esta versión muestra una clara conciencia de la evolución de Agustín, conciencia que, según hemos podido ver, Tomás posee en $D e$ Veritate q. 15. Tal conciencia se manifiesta aquí en que una vez más menciona la bipartición del hombre, que deja al hombre como la racionalidad y a la mujer como la sensualidad, como algo que Agustín no mantuvo, sino que fue cambiado por la tripartición posterior en que la mujer representa la intermedia razón inferior ${ }^{21}$. En la reportatio vulgata del mismo texto no hay alusión alguna a Agustín, sino que Tomás mismo hace primero la bipartición, para luego corregirse diciendo que es más correcto comparar la mujer a la razón inferior ${ }^{22}$.

A la luz de estos textos podemos dejar como razonablemente establecida no sólo la fuerte presencia de la distinción en los términos estrictamente agustinianos que cabe esperar en un comentador de las Sententiae, sino también una conciencia de la evolución de Agustín que no puede provenir de Pedro Lombardo, sino que es propia del agustinismo del siglo XIII, menos dependiente de florilegios y más de la lectura directa de Agustín ${ }^{23}$.

20 De Veritate q. 15, a.4, ad 7. "Ad septimum dicendum, quod Augustinus in Lib. contra Manichaeum non eodem modo exponit illa tria, sicut in libro de Trinit. In XII de Trinitate enim serpentem attribuit sensualitati, mulierem inferiori rationi, virum superiori; sed in Lib. contra Manichaeum, serpentem sensui, mulierem concupiscentiae sive sensualitati, virum rationi. Unde patet quod ratio non sequitur".

21 Reportatio Reginaldi de Piperno Super I Cor., cap. 11 vs. 10 "Augustinus autem aliter exponit dicens quod vir et mulier accipiuntur hic pro quodam interiori coniugio. In anima enim nostra est quoddam spirituale coniugium, ita ut vir assignetur aliquando ab Augustino pro ipsa ratione, et sensualitas pro muliere. In libro vero de Trinitate, ponit sensualitatem loco serpentis, loco viri rationem superiorem, inferiorem vero loco mulieris".

22 Reportatio vulgata: Super I Cor., cap. 11 1. 1. "Nam sensualitas foeminae comparatur, ratio vero viro, per quem sensualitas regi debet. Unde et caput eius dicitur. Vel potius ratio inferior, quae inhaeret temporalibus disponendis, mulieri comparatur; viro autem ratio superior, quae vacat contemplationi aeternorum, quae caput inferioris dicitur".

${ }^{23}$ Para tales cambios véase I. Backus (ed.) The Reception of the Church Fathers. 


\section{LA COMPRENSIÓN TOMASIANA DEL BINOMIO}

Consideraremos a continuación tres campos en que puede ser constatado el modo en que Tomás de Aquino se apropia de la posición de Agustín. En primer lugar, el modo en que la distinción entre razón superior e inferior se vincula con la discusión sobre géneros de vida; en segundo lugar, el modo en que Tomás de Aquino entiende la relación entre esta distinción y las diversas facultades del hombre; en tercer lugar, el uso de la distinción en la evaluación antropológica y moral de la delectación morosa.

\subsection{Los géneros de vida}

La distinción entre formas de conocimiento se encuentra desde luego estrechamente entrelazada con la pregunta por los géneros de vida. Así, a la unidad de las formas de conocimiento en Platón corresponde la figura unitaria del rey-filósofo, y a la distinción aristotélica entre phronesis y sophia corresponde que la vida política y la filosófica estén configuradas como alternativas claramente distintas. Esta segunda variante la sigue por supuesto Tomás de Aquino. Con todo, también aquí se puede encontrar rastros de la posición agustiniana. En efecto, en Super Ioannem, en concreto en 18:15 y seguían a Jesús Simón Pedro y otro discípulo [el mismo Juan], Tomás introduce dos modos de seguimiento, dos géneros de vida representados por Pedro y Juan. Ellos son puestos como respectivos ejemplos de la vida activa y la contemplativa, y para designar estos modos de vida Tomás de Aquino acude aquí una vez más a la distinción entre razón superior e inferior ${ }^{24}$. Tomás de Aquino utiliza la ocasión para una defensa de la primacía de la vida contemplativa, notando que en el verso 16 del mismo capítulo 18 Juan le indica a una portera que deje entrar a Pedro. Así, la vida contemplativa es retratada como una que goza de cierta anticipación en el seguimiento de Cristo; pero significativamente se trata de una anticipación no desconectada de la del otro tipo de seguimiento, sino abriéndole paso $^{25}$. En tal planteamiento está claro que no estamos ante un único género de vida, como en la tradición platónica, pero tampoco estamos estrictamente en la posición de Aristóteles, pues los dos modos de vida se

\footnotetext{
${ }^{24}$ Super Ioannem, cap. 18 1. 3. "Mystice autem per hos duos discipulos duae vitae intelliguntur, quae Christum sequuntur, scilicet activa, quae signatur per Petrum, et contemplativa, quae per Ioannem. Et activa quidem sequitur Christum obediendo, supra X, 27: oves meae vocem meam audiunt, contemplativa vero cognoscendo et contemplando".

25 Super Ioannem, cap. 18 1. 3. "Per quod mystice datur intelligi quod per contemplativam introducitur ad Christum activa vita: sicut enim ratio inferior dirigitur per superiorem, ita activa per contemplativam".
} 
encuentran vinculados por la unión en cierto tipo de seguimiento, o por su encaminamiento en una misma dirección.

Ahora bien, Agustín jamás recurre a las nociones de razón superior e inferior para tratar los géneros de vida, pero sí ilustra los géneros de vida mediante alusión a parejas bíblicas como María y Marta o Raquel y Lea ${ }^{26}$, y entre estas parejas se encuentra precisamente la de Juan y Pedro. Agustín recurre a esta pareja en el último de sus tratados sobre el Evangelio de Juan, tratado que se inicia con un contraste entre los dos géneros de vida en los siguientes términos:

La iglesia conoce dos géneros de vida que le han sido transmitidos y confiados por la divinidad. Uno de éstos consiste en la fe, el otro en la visión; el uno en la peregrinación temporal, el otro en la residencia eternal; uno en el trabajo, el otro en el reposo; uno en el camino, el otro en la patria; uno en el esfuerzo de la acción, el otro en el premio de la contemplación; el uno evita el mal y hace el bien, el otro no tiene mal que evitar sino un bien del cual gozar (...); uno distingue (discernit) entre el bien y el mal, el otro sólo capta (cernit) lo bueno; uno es por tanto bueno y sin embargo infeliz, el otro mejor y feliz. Al primero lo representa el apóstol Pedro, al otro Juan ${ }^{27}$.

Lo que encontramos aquí son por supuesto loci típicos en esta materia (trabajo-reposo, fe-visión, via-patria, miseria-beatitudo), además de una clara afirmación de la primacía de la vida contemplativa. No se está hablando aquí de aspectos distintos que integren un único género de vida mixto. Se trata, por el contrario, de dos géneros de vida claramente diferenciados, uno de los cuales parece menos propio de la vida terrenal, pero que sin embargo es representado en esta vida por al menos algunas personas. Tomás de Aquino no

${ }^{26}$ Para María y Marta véase los sermones 104 y 179, para Raquel y Lea Contra Faustum, XXII, 52-58.

${ }^{27}$ In Ioannis Evangelium tractatus CXXIV, 124, 5. "Duas itaque vitas sibi divinitus praedicatas et commendatas novit Ecclesia, quarum est una in fide, altera in specie; una in tempore peregrinationis, altera in aeternitate mansionis; una in labore, altera in requie; una in via, altera in patria; una in opere actionis, altera in mercede contemplationis; una declinat a malo et facit bonum, altera nullum habet a quo declinet malum, et magnum habet quo fruatur bonum; una cum hoste pugnat, altera sine hoste regnat; una fortis est in adversis, altera nihil sentit adversi; una carnales libidines frenat, altera spiritalibus delectationibus vacat; una est vincendi cura sollicita, altera victoriae pace secura; una in tentationibus adiuvatur, altera sine ulla tentatione in ipso adiutore laetatur; una subvenit indigenti, altera ibi est ubi nullum invenit indigentem; una aliena peccata ut sua sibi ignoscantur ignoscit, altera nec patitur quod ignoscat, nec facit quod sibi poscat ignosci; una flagellatur malis, ne extollatur in bonis, altera tanta plenitudine gratiae caret omni malo, ut sine ulla tentatione superbiae cohaereat summo bono; una bona et mala discernit, altera quae sola bona sunt cernit: ergo una bona est, sed adhuc misera; altera melior et beata. Ista significata est per apostolum Petrum, illa per Ioannem". En De consensu evangelistarum, IV, 10, 20 ya se encuentra una reflexión en ese sentido. 
sólo sigue a Agustín en la ilustración, sino, como hemos visto, además complementa esto con una herramienta agustiniana -razón superior e inferior- que el propio Agustín no usa en ese campo. Con todo, es mucho más sustantiva, como veremos a continuación, la elaboración que Tomás hace de esta distinción en el contexto de las discusiones antropológicas del De Veritate.

\subsection{Las diversas facultades de la persona humana}

Un segundo contexto en el que Tomás de Aquino se refiere a la razón superior e inferior es al investigar si se trata de dos potencias intelectivas diferentes. La cuestión se plantea en el De veritate y en la Summa Theologiae y en ambos lugares formula esta pregunta después de haber resuelto que el intelecto y la razón no son dos potencias diferentes ${ }^{28}$. La semejanza entre las dos preguntas se debe a que en ambos casos hay una distinción entre un uso del entendimiento más perfecto o elevado y otro menos perfecto ${ }^{29}$.

En el caso de la obra temprana De Veritate la respuesta a esta pregunta antropológica se vincula con la cuestión moral a la que dedicará los artículos siguientes. Primero clarifica que son dos funciones de una misma potencia, para luego establecer el papel de cada una de estas funciones en la deliberación moral. Puesto que son dos funciones de una misma potencia es más evidente que la relación entre ambas es estrecha, pues se influyen recíprocamente.

Se considerará más detenidamente el artículo 2 de la cuestión 15 del De Veritate en la que la argumentación se fundamenta tanto en la teoría agustiniana que explica que la razón superior atiende a las cosas superiores al intelecto humano y la inferior a las que están bajo el entendimiento, como en la teoría aristotélica de la especificación de las facultades por sus objetos y por sus actos. En este artículo Tomás de Aquino pregunta directamente si la razón superior e inferior se pueden distinguir como dos facultades o potencias diferentes en el hombre, cuestión a la que responde negativamente. La explicación es que puesto que el entendimiento es una potencia superior, inmaterial, sus actos no se especifican por su objeto, ya que éste es siempre un objeto de orden inmaterial; en último término el objeto es el ente, aquello que es. La especificación se da por la razón formal bajo la que se considera el objeto. Por ejemplo, así se distinguen la inteligencia y la voluntad, en cuanto que tienen como objeto, respectivamente, el ser en cuanto verdadero o en cuanto bueno.

${ }^{28}$ Cf. De Veritate, q.15, aa. 1 y 2 y Summa Theologiae, I, q. 79, aa. 8 y 9.

${ }^{29}$ La cuestión no es original en Tomás de Aquino, pues desde antiguo se ha presentado la contraposición entre el nous y la dianoia, entre la mens y la ratio. 
Esta diferencia no se da entre la razón superior y la inferior que comparten la razón formal de lo verdadero. Se distinguen solamente porque ejercen dos tareas o funciones diferentes, a saber, la que considera cosas de naturaleza superior a la propia o de naturaleza inferior. Las naturalezas superiores, objetos de la razón superior, son aquellas realidades respecto de las cuales el intelecto racional es inferior. En este caso, el alma contempla la misma verdad y la naturaleza de las cosas. Aunque su acto propio es el contemplar, Tomás también le asigna a esta razón la capacidad de tomar de aquellas naturalezas la razón o el ejemplar de la operación, es decir le asigna también una función práctica a la que se atenderá en el análisis de la delectación morosa. La razón superior (la que contempla la verdad) aprehende la naturaleza superior en cuanto que ésta es inmaterial en sí misma. Las naturalezas inferiores, objetos de la razón inferior, son aquellas realidades respecto de las cuales el alma es superior a ellas. La razón inferior aprehende las naturalezas inferiores inmaterializándolas por el acto cognoscitivo. Por eso estas naturalezas tienen un ser más noble en el alma que en sí mismas. La razón inferior actúa respecto de ellas, ya sea convirtiéndolas en objeto de contemplación, ya sea disponiendo de estos conocimientos como criterios que regulen la acción. Es decir, en ambas formas de usar la razón se da la doble capacidad de orientar la consideración a la contemplación o a la acción.

Tomás de Aquino ha seguido en este artículo la idea agustiniana de que el entendimiento tiene objetos que son superiores y hacia los que cabe más bien una actitud contemplativa y otros objetos que al ser inferiores dirigen la acción. Sin embargo esta distinción no es obstáculo para una relación estrecha entre ambos usos del entendimiento. También está claramente presente la influencia aristotélica de la que se sirve para establecer aquello que distingue a las facultades y por qué en este caso no se debe afirmar que se trata de facultades diversas ${ }^{30}$.

Una vez aclarado este punto, podemos ver el uso que Tomás hace de la razón superior e inferior en materia moral, concretamente en la delectación morosa.

${ }^{30}$ Más específicamente las referencias a Aristóteles que hace Tomás de Aquino en $D e$ Veritate q. 15, a. 2 en el corpus del artículo, se pueden dividir en dos tipos: las que atienden a la cuestión de las facultades: cómo se distinguen entre sí y las que se refieren al objeto del entendimiento. Con respecto a las facultades, cita Metafísica IX, 8, 1050a 7 y Física V, 1, 224b 7. Para explicar que el objeto del entendimiento es infinito: todos los seres, se apoya en De anima III, 5, 430a 16 y Metafísica VI, 4, 1027b 25. Este segundo tipo de textos respaldan la idea de que lo que distingue a la voluntad y al entendimiento es la razón formal, pues ambas tienen un objeto inmaterial, en cambio la razón superior y la inferior tienen la misma razón formal. Estas citas muestran que Aristóteles es la fuente de Tomás para todo lo relativo a las facultades. 


\subsection{El uso de la razón superior e inferior en el plano moral: la delectación morosa}

Un lugar importante para comprender el uso que Tomás de Aquino hace de la distinción entre razón superior e inferior es la cuestión moral de la delectación morosa, tema que es clásico en la teología moral y que podemos ver en Tomás desde In IV libros Sententiarum. Son tres los lugares en el que se trata de una manera explícita. En primer lugar, en Sententiarum 2, d. 24, q.3 en la que se pregunta por los pecados de sensualidad y la relación de ésta con la razón superior e inferior. Concretamente en el artículo 4 se analiza la cuestión de la delectación morosa que se refiere a un deleite sensual que no es súbito y que por lo mismo implica una cierta deliberación de la razón. Como se ha visto más arriba (n. 3) Pedro Lombardo inserta a propósito de este tema los textos agustinianos que dan pie al binomio razón superior e inferior. En segundo lugar, en los artículos 4 y 5 de la cuestión 15 del De Veritate y en tercer lugar, prácticamente con el mismo esquema, en la Summa Theologiae I-II, 74, 6 y 7. Se ha dejado de lado In IV libros Sententiarum por razones de espacio y porque los temas más relevantes se exponen de manera similar en las otras dos obras arriba mencionadas. Nuestro interés se centra en estos textos en la articulación que se da entre ambas formas de razón y la influencia agustiniana en el modo como Tomás de Aquino aborda esta temática. Se procederá primero describiendo los aspectos que para nuestro objetivo son relevantes, tanto en el texto del De Veritate como en la Summa Theologiae, para después formular algunas conclusiones que se pueden extraer de estos textos.

Para establecer el tipo de pecado o falta moral en la que se incurre por la delectación morosa es necesario dilucidar previamente si en la razón superior e inferior puede haber pecado. Este tema ocupa el artículo 3 de la cuestión 15 del De Veritate. Tal como señala A. M. González en la Introducción a su traducción de esta cuestión, el término pecado se presenta en el artículo de un modo que puede ser ambiguo, porque se atribuye más bien a la razón que a la voluntad. Pero, aunque en términos absolutos el pecado sea del hombre y de su voluntad, la inclinación de esta potencia superior se origina en algún juicio de la razón ${ }^{31}$. Es aquí donde la distinción entre razón superior e inferior juega un papel importante para explicar dos formas de inferencias de la razón que conducen al pecado. Éstas son: en primer lugar, la inferencia que tiene como punto de referencia la aprehensión del fin último del hombre y su sometimiento a los mandatos divinos y que compete a la razón superior: como

31 A.M. González, Introd., trad. y notas al De Veritate, 15, Acerca de la razón superior e inferior, p. 19. 
ocurre cuando alguien delibera acerca de lo que se ha de hacer partiendo de que algo es aceptado por Dios o preceptuado por la ley divina (corpus). En segundo lugar, aquella inferencia que se deriva más bien de aprehensiones ligadas a la sensualidad, a los apetitos concupiscibles e irascibles y que considera la moralidad de la acción atendiendo más bien a motivos humanos o causas inferiores, por ejemplo por considerar la torpeza del acto, la dignidad de la razón, la ofensa a los hombres (corpus). El error en estas dos formas de inferencia se llama pecado, aunque el consentimiento, como ya se dijo, provenga de la voluntad. Se atribuye este error a la razón superior cuando se equivoca en la inspección del fin último, y a la razón inferior cuando yerra respecto a la delectación o a la complacencia en la delectación, porque esta razón debe gobernar la sensualidad ${ }^{32}$. Concluye el cuerpo del artículo afirmando que en ambos usos de la razón puede haber pecado. En los dos artículos siguientes el análisis se centra en la delectación morosa estableciendo en qué casos el pecado es venial o mortal ${ }^{33}$.

En De Veritate 15, 4 se pregunta si la delectación morosa es pecado mortal y en qué razón radica. La cuestión que se discute es si la delectación que trae consigo la consideración de un acto sensual desordenado tiene la misma gravedad moral que la ejecución externa del acto. En términos absolutos esta delectación sensual es pecado mortal, porque se aprueba y consiente un acto que de suyo es grave. En algunas respuestas a las objeciones se considera el papel que juegan la razón superior y la inferior. Por ejemplo, en la respuesta a la $6^{\mathrm{a}} \mathrm{ob}-$ jeción se hace notar que la aversión al pecado es, de alguna manera, común a los dos usos de la razón puesto que la razón superior regula a la inferior. Si la primera rechaza el pecado, la segunda también. La misma idea está en la respuesta a la objeción 11, en la que se explica que la fuerza del precepto divino llega hasta la razón inferior, porque ésta participa del régimen de la razón superior.

El aspecto que ahora interesa destacar es que la razón superior se dirige o tiene como objeto las verdades eternas, de las que participa la inferior.

\footnotetext{
${ }^{32}$ Hay una alusión directa a Agustín, concretamente a De Trinitate, XII c. 12 (PL 42, 1007). La sensualidad o apetito sensitivo en cuanto tiene por naturaleza obedecer a la razón se llama racional, pero no es propiamente racional. En el orden que se da entre la razón superior y la inferior está también el orden al que se somete la sensualidad: "la razón superior regula la inferior y la razón inferior a la sensualidad" (In II Sent. d. 24, q. 3, a. 1 ad 5). Cf. J.F. Sellés, Introd., trad. y notas al De Veritate 25, Acerca de la sensualidad.

${ }^{33}$ En De Veritate q.15, a. 3 hay sólo una cita explícita a Aristóteles: Etica Nicomaquea, VII, 8,1151 a 16. El contexto de la cita es el tema del licencioso y el incontinente y Tomás de Aquino la utiliza en este artículo para establecer una comparación entre lo operable y lo especulativo. En ambos casos se puede dar una resolución a partir del principio último. En el caso de lo operable, cuando se resuelve a la luz del principio último, se resuelve conforme a la razón superior. Del mismo modo las ciencias se perfeccionan cuando el conocimiento se contrasta o se ilumina por los primeros principios. Este texto es bastante coherente con la doctrina agustiniana de la relación entre ciencia y sabiduría, quizás por eso lo incluye Tomás.
} 
Esta misma idea está presente en el artículo $5^{34}$ en el que se pregunta si en la razón superior puede haber pecado venial, porque parece que al moverse por las razones eternas sólo peca mortalmente. La respuesta es que sí puede pecar venialmente, aunque su objeto sea una verdad o razón eterna, cuando es un acto repentino en el que no hay deliberación. En cambio, cuando la razón superior juzga acerca de cosas temporales, necesariamente tiene que haber deliberación, porque su juicio se realiza a la luz de las verdades eternas. Resulta así que si la materia se encuentra en el género del pecado mortal, el acto de la razón superior será siempre pecado mortal, si la materia se encuentra en el género del pecado venial, será venial. Queda claro que la razón superior actúa siempre bajo la luz o la dirección que imprime la consideración de las verdades eternas. Esta consideración puede ser deliberativa o no en el caso de su materia propia, es decir, las verdades eternas, pero siempre es deliberativa en el caso de las cosas temporales, porque las juzga a la luz de las verdades eternas.

Se pueden ya adelantar algunas conclusiones a partir del análisis de estos textos. La afirmación de que son dos modos de operar de la misma razón, permite establecer la conexión entre ambos. La contemplación de las verdades eternas influye en la comprensión de las cuestiones contingentes. A la vez estas últimas ayudan a penetrar mejor las eternas perfeccionándose mutuamente. Pero la primacía del juicio que procede de la consideración de las verdades eternas es clara y se corresponde con la primacía que Agustín otorga a la búsqueda de una vida buena, como dirección que marca la conducta moral. Las verdades eternas son la guía última o principio último del actuar humano. Se establece una preeminencia del conocimiento del fin del hombre tanto en su operación y conducta práctica, como también en la comprensión de las creaturas. La sabiduría que pertenece a la razón superior es la sapientia agustiniana y no la aristotélica, al menos en estos casos. (En otros contextos, Tomás usará más la sabiduría aristotélica).

El texto paralelo de la Summa Theologiae, I-II, q. 74 artículos 6, 7, 9 y 10 nos permitirá afinar las ideas expuestas a partir del De Veritate y verificar que Tomás de Aquino mantiene la línea de interpretación de Agustín que a propósito de esta obra hemos señalado. La cuestión 74 trata del sujeto del pecado y el artículo 6 se pregunta si está en la razón el pecado de la delectación morosa. En el cuerpo del artículo Tomás argumenta que hay pecado cuando la razón yerra en la dirección de las pasiones interiores, como también en la dirección de los actos externos. En la dirección de los actos internos se equivoca de un modo positivo o negativo: cuando impera las pasiones ilícitas o cuando

\footnotetext{
${ }^{34}$ Cf. De Veritate, q.15, a. 5.
} 
no refrena el movimiento ilícito de la pasión. En esta última situación se da la delectación morosa porque consiste en entretenerse en la pasión ilícita sin desecharla. Visto así, el pecado de delectación morosa está en la razón, particularmente en la razón inferior. Esta conclusión se realiza en el sed contra donde aparece el binomio razón superior e inferior. Tomás cita a Agustín e interpreta que éste entiende por la mujer la razón inferior ${ }^{35}$. Concluye en el mismo sed contra que si está involucrada en el consentimiento la razón inferior, se puede hablar de que en el pecado de delectación morosa está presente la razón.

En el artículo $7^{36}$ se refiere directamente al papel que juega la razón superior en el consentimiento del acto y, por lo tanto en la comisión del pecado. Siempre el trasfondo del artículo es Agustín en el De Trinitate XII. La mujer (razón inferior) ha dado el alimento ilícito al varón (razón superior), luego también la razón superior consiente en el acto del pecado. Explica en el cuerpo del artículo que el consentimiento supone un juicio de la razón práctica. Este juicio puede realizarse conforme a principios naturales o también a los principios que proceden de la ley divina. Le parece lógico a Tomás que la última sentencia que determina el juicio provenga de la razón superior que atiende a las razones eternas. La razón inferior también participa del acto pecaminoso, pero más bien en la delectación misma que es el preámbulo que induce al acto, aunque advierte que la razón superior puede juzgar también de la delectación, porque lo superior juzga de lo inferior y no al revés. En la respuesta a la segunda objeción se refuerza el papel de la razón superior en la delectación ya sea porque desprecia la ley eterna o porque la ignora. La respuesta a la tercera objeción admite un cierto matiz al conceder que la razón inferior puede acceder a la delectación morosa antes de que se realice el juicio de la razón superior. Aquí el consentimiento es de la razón inferior, porque delibera conforme a razones temporales. Pero si persevera en tal consentimiento considerando las razones eternas, entonces el consentimiento es de la razón superior ${ }^{37}$.

También aparece la distinción entre estas dos formas de razón en los artículos 9 y 10 de la misma cuestión 74 en los que se pregunta si puede haber pecado venial en la razón superior, en cuanto que es rectora de las facultades inferiores (art. 9) y considerada en sí misma (art. 10). En la misma línea del artículo quinto del De Veritate, se explica en el artículo 9 que el consentimiento está precedido de la deliberación que, en el caso de la razón superior, es siempre respecto a las verdades o razones eternas. Hay una diferencia con respecto al De Veritate, pues se admite que la razón superior puede pecar venialmente

35 Ver De Trinitate XII: ML 42, 1007-1008

${ }^{36}$ Cf. Summa Theologiae, I-II, q. 74, a. 7.

${ }^{37}$ Cf. Summa Theologiae, I-II, q. 74, a. 7, ad 2 y ad 3. 
cuando el objeto sobre el que delibera no es contrario a las razones eternas, de manera que la persona no se separa del fin último. El pecado mortal se da cuando hay separación del fin último, esto es cuando hay desprecio de las razones eternas. En el artículo 10 se repite la doctrina del De Veritate al afirmar que hay pecado venial en la razón superior considerada en sí misma cuando se trata de una falta en sí grave, pero fruto de un movimiento repentino en el que no hay pleno consentimiento. Se refiere concretamente al caso de pecados que atañen directamente a la razón superior, por ejemplo, pecados contra la fe. Aunque son en sí pecados mortales, pueden ser veniales por el tipo de consentimiento o por la característica de éste. Si se trata de un movimiento repentino en el que no se ha consultado las verdades o razones eternas o no se ha deliberado con respecto a ellas, sino que se actúa movido por un impulso repentino, se comete un pecado venial. Si hay deliberación y persiste el movimiento, entonces sí es pecado mortal.

En resumen, la razón superior consiente al pecado grave cuando delibera respecto a las verdades eternas; si no hay tal deliberación, no se comete pecado mortal, sino venial en el caso de una materia grave, por causa del tipo de consentimiento. Si la materia es leve, porque no separa a la persona del fin último, se puede dar pecado venial en la razón superior por razón de la materia del pecado. La consideración del pecado se especifica por su género y también por el tipo de consentimiento o de deliberación. Por su género es grave o venial; por el tipo de deliberación, aun cuando el género sea grave, puede ser venial por tratarse sólo de un movimiento repentino.

Vemos confirmada en este texto la primacía de la razón superior como guía de la conducta humana. La consideración de las verdades eternas comandan, en último término, la gravedad del pecado, ya sea porque éste supone un apartarse de ellas porque la razón las desprecia, ya sea porque al no haber propiamente deliberación con respecto a ellas, se incurre sólo en pecado venial. El análisis del uso que Tomás de Aquino hace de la razón superior e inferior en el caso de la delectación morosa ha evidenciado que sigue de cerca la interpretación de Agustín en la imagen de la relación entre el hombre y la mujer (razón superior e inferior respectivamente).

\section{CONCLUSIONES}

En base a lo que hemos considerado, se puede señalar que si bien Mulligan tiene razón respecto del limitado uso de esta pareja conceptual en Tomás de Aquino, un detenido análisis de su uso permite notar que estamos ante un caso significativo de agustinismo en la filosofía de Tomás. Es relevante porque expresa no sólo el agustinismo común de la tradición, sino una apropiación que 
en algunos puntos es exclusiva del aquinate, revelando incluso la conciencia que él tiene de la evolución de Agustín en esta materia. En dicha concepción madura de Agustín, como se recordará, hay una serie de relaciones recíprocas entre estas dos formas de conocimiento, elemento que se encuentra claramente conservado en los distintos usos que Tomás de Aquino hace de la razón superior e inferior. En efecto, las interrelaciones entre estos dos usos de la razón están ampliamente ilustradas en los textos que se han analizado ${ }^{38}$.

Se puede también afirmar que en ambos autores salta a la vista la primacía de la razón superior como orientadora de la conducta moral, justamente por la consideración de las verdades eternas que son las que, en último término, definen el actuar moral porque señalan la dirección de la vida buena. Esta relación tiene un claro antecedente en la concepción agustiniana de la necesidad del consentimiento de la sabiduría en la concreción del actuar moral. El análisis de las formas de pecado en la delectación morosa ilustra esta conclusión.

La versatilidad de las dos formas de ejercitar la razón se refuerza en la Summa Theologiae ${ }^{39}$ donde se establece una relación dialéctica entre ambas formas de razón: por un proceso de búsqueda, a partir de la consideración de lo temporal, se llega a lo eterno. Por un proceso de deducción, juzgamos lo temporal a la luz de lo eterno. Ambas formas de operar de la razón se comunican entre sí de una manera estrecha, porque las verdades temporales y las eternas están subordinadas entre sí, de modo que unas sirven de medio para conocer las otras. Esta relación es el argumento central del artículo para refutar que se trate de dos potencias diferentes. La referencia a Agustín es explícita en este texto al atribuir a la razón superior el hábito de sabiduría y a la inferior el de ciencia y al guiarse en la explicación por la comprensión que tiene Agustín de estas dos funciones de la razón ${ }^{40}$.

Es también relevante que la única referencia a Aristóteles en el texto de la Summa Theologiae, que se ha mencionado arriba, le sirva a Tomás de

38 Además de los ya señalados en el artículo, se pueden mencionar: De Veritate, q. 15, a. 4, ad 6 donde se explica que también la razón inferior puede tener aversión al pecado, al participar de la conversión hacia Dios de la razón superior. En el mismo artículo el ad 11 explica que la fuerza del precepto divino llega hasta la razón inferior porque ésta participa del régimen de la razón superior. Ver también De Veritate, q. 15, a. 5, ad 4 que explica la relación inversa, es decir, la razón inferior puede pervertir a la superior que, aunque no está unida a la carne, recibe de la inferior la corrupción que ésta puede tener.

39 Cf. Summa Theologiae, I, q. 79, a. 9.

${ }^{40}$ Cf. Summa Theologiae, II-II, q. 8, a. 6 en la que se explica la unión entre los hábitos de ciencia y de sabiduría. Al explicar el don de entendimiento, Tomás hace ver que el don de ciencia versa tanto sobre lo especulativo como lo práctico. La diferencia se establece más bien en el objeto del juicio al que adhiere o al que rechaza la voluntad. Según esto, el don de sabiduría juzga acerca de las cosas divinas y el de ciencia sobre las cosas creadas, pero en ambos casos puede referirse a lo especulativo o lo práctico. 
Aquino para aclarar que la distinción entre la razón superior e inferior no se equipara con la parte científica del alma y la que opina y razona ${ }^{41}$. No son equiparables porque la razón superior considera verdades que están por encima de ella, es decir, las verdades eternas. En cambio, la parte científica del alma trata también acerca de las cosas temporales en la medida que en ellas hay razones necesarias, por ejemplo en las ciencias naturales y en las matemáticas hay nociones necesarias. La razón inferior tampoco es equivalente a la parte de la razón que opina y razona, porque el objeto de esta parte es aquello que es contingente, es decir, un objeto diferente al de la razón inferior que considera las cosas subordinadas a las eternas, pero no en su calidad de contingentes. El único punto común con Aristóteles es que también él considera que las diversas partes de la razón constituyen una sola potencia, del mismo modo que la razón superior e inferior.

Un último argumento para reforzar el carácter agustiniano de esta distinción en Tomás de Aquino, es la nula referencia a la ratio particularis o cogitativa. Como es sabido, el aquinate recoge de la tradición árabe-aristotélica la doctrina de un sentido interno llamado estimativa en los animales y cogitativa en la persona humana. Este sentido, en el caso del hombre, opera como una razón particular porque compara aquello que le presenta la imaginación con lo que es conveniente o disconveniente en una determinada acción. En el análisis de la delectación morosa, podría haberse mencionado la acción de este sentido interno que está ligado más directamente a la acción moral. En De veritate 15, 2 ad 7 menciona el papel de la imaginación, como potencia que tiene un papel específico, pero no la vincula con la cogitativa. Se puede interpretar esta ausencia como una señal más de la cercanía que tiene Tomás en el análisis de este binomio a Agustín, puesto que no le da cabida a una doctrina de raíz aristotélica ${ }^{42}$.

\section{BIBLIOGRAFÍA CITADA}

Agustín, Confessiones, Turnhout, Brepols, 1981. (Corpus Christianorum Series Latina; 27).

Agustín, Contra Faustum, Viena, F. Tempsky, 1891. (Corpus Scriptorum Ecclesiasticorum Latinorum; 25, 1).

${ }^{41}$ Cf. Ética Nicomaquea VI, 1139a 6.

${ }^{42}$ Cf. Summa Theologiae I, q. 78, a. 4 donde Tomás de Aquino habla de la cogitativa como uno de los sentidos internos. Ver también De Veritate, q. 10, a. 5 en la que se explica el papel de la cogitativa en la acción práctica. Agradecemos la advertencia de uno de los revisores del artículo sobre la ratio particularis que nos llevó a examinar su posible vinculación con el binomio ratio inferior y superior. 
Agustín, De Academicis, Turnhout, Brepols, 1970. (Corpus Christianorum Series Latina; 29)

Agustín, De consensu evangelistarum, Viena, F. Tempsky, 1904. (Corpus Scriptorum Ecclesiasticorum Latinorum; 43).

Agustín, De diversis quaestionibus, Turnhout, Brepols, 1970. (Corpus Christianorum Series Latina; 44).

Agustín, De Genesi contra Manichaeos Viena, Verlag der Österreichischen Akademie der Wissenschaften, 1998. (Corpus Scriptorum Ecclesiasticorum Latinorum; 91).

Agustín, De Trinitate, Turnhout, Brepols, 1968. (Corpus Christianorum Series Latina; 50/50A).

Agustín, San, In Ioannis Evangelium tractatus, Turnhout, Brepols, 1954. (Corpus Christianorum Series Latina; 36).

Agustín, Sermones, Stromata Patristica et Mediaevalia, Utrecht, Spectrum, 1950.

Aquino, Tomás de, Quaestiones disputatae De veritate, Corpus Thomisticum. Aquino, Tomás de, Scriptum super Sententiis, Corpus Thomisticum.

Aquino, Tomás de, Super Ioannem, Corpus Thomisticum.

Aquino, Tomás de, Summa Theologiae, Corpus Thomisticum.

Aristóteles, Metafísica, traducción de Valentín García Yebra, Madrid, Gredos, 1990.

Aristóteles, Acerca del alma, traducción de Tomás Calvo Martínez, Madrid, Gredos, 1988.

Aristóteles, Física, traducción de Guillermo R. de Echandía, Madrid, Gredos, 1995. Aristóteles, Ética Nicomaquea, traducción de Julio Pallí Bonet, Madrid, Gredos, 1988.

Backus, Irena, (ed.), The Reception of the Church Fathers in the West 2 vols., Leiden, Brill, 1997.

Chenu, Marie-Dominique, O.P., Ratio superior et inferior. Un cas de philosophie chrétienne, "Revue des sciences philosophiques et théologiques" 29 (1940), pp. 84-89.

Dauphinais, Michael; David, Bary; Levering, Matthew; (ed.), Aquinas the Augustinian, Washington, DC, CUA Press, 2007.

González, Ana Marta, Introducción, traducción y notas al De Veritate, 15, Acerca de la razón superior e inferior, Pamplona, Servicio de Publicaciones de la Universidad de Navarra, 1999. (Cuadernos de Anuario Filosófico; 87).

Hessen, Johannes, Die Begründung der Erkenntnis nach dem heiligen Augustinus, Münster, Aschendorff, 1916.

Lombardo, Pedro, Sententiae in quattuor libros distinctae, Roma, Grottaferrata, 1971. 
MacIntyre, Alasdair, Tres versiones rivales de la ética. Enciclopedia, genealogía y tradición, Madrid, Rialp, 1992.

Mulligan, Robert, S.J., Ratio superior and ratio inferior: the Historical Background, "The New Scholasticism" 29/1 (1955) pp. 1-32.

Mulligan, Robert, S.J., Ratio inferior and ratio superior in St. Albert and St. Thomas, "The Thomist" 19 (1956) pp. 339-367.

Nash, Ronald, The Light of the Mind: St. Augustine's Theory of Knowledge, Lexington, University Press of Kentucky, 1969.

Osborne, Thomas, The Augustinianism of Thomas Aquinas's Moral Theory, "The Thomist" 67 (2003) pp. 279-305.

Plotino, Enéadas, traducción de Jesús Igal, Madrid, Gredos, 1998.

Reportatio Reginaldi de Piperno Super I Cor., Corpus Thomisticum.

Reportatio vulgata: Super I Cor, Corpus Thomisticum.

Sellés, Juan Fernando, Introducción, traducción y notas al De Veritate 25, Acerca de la sensualidad, Pamplona, Servicio de Publicaciones de la Universidad de Navarra, 2001. (Cuadernos de Anuario Filosófico; 121).

Svensson, Manfred, Theorie und Praxis bei Augustin. Eine Verhältnisbestimmung Friburgo, Alber Verlag, 2009.

Weithman, Paul, Augustine and Aquinas on Original Sin and the Function of Political Authority, "Journal of the History of Philosophy" 30 (1992) pp. 353-376.

Fecha de recepción del artículo: enero 2012

Fecha de aceptación y versión final: septiembre 2012 